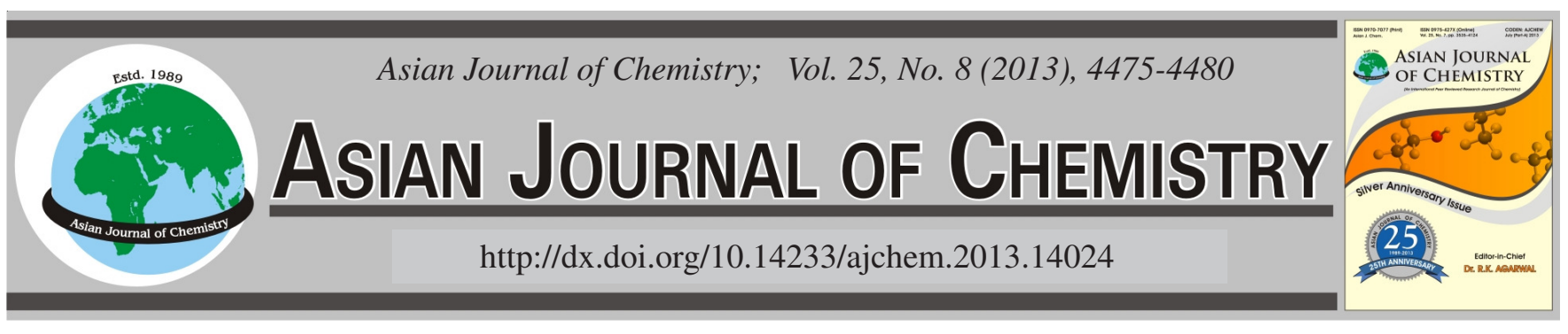

\title{
Study on the Interaction Between Salvianolic Acid B and Bovine Serum Albumin by Spectroscopic Techniques
}

\author{
Qing Zhu ${ }^{1}$, Mei $\mathrm{WANG}^{2}$, Feng LiU ${ }^{3}$ and XiaO $\mathrm{WANG}^{3, *}$
}

${ }^{1}$ Qilu Hospital of Shangdong University, 107 West of Wenhua Street, Jinan, Shandong 250012, P.R. China

${ }^{2}$ Shandong Normal University, 88 East of Wenhua Street, Jinan, Shandong 250014, P.R. China

${ }^{3}$ Shandong Analysis and Test Center, Shandong Academy of Sciences, 19 Keyuan Street, Jinan, Shandong 250014, P.R. China

*Corresponding author: Fax: +86 531 82964889; Tel: +86 531 82605304; E-mail: wangxiao2008@yahoo.cn

(Received: 7 May 2012;

Accepted: 15 February 2013)

AJC-12992

\begin{abstract}
Under simulated physiological conditions, the interaction between salvianolic acid B and bovine serum albumin was investigated using fluorescence spectroscopy, synchronous fluorescence spectroscopy, circular dichroism and ultraviolet spectroscopy at different conditions. As a result, the binding constant $(\mathrm{K})$, the numbers of binding sites $(\mathrm{n})$, the binding distance $(\mathrm{r})$ and the thermodynamic parameters enthalpy change $\left(\Delta \mathrm{H}^{\circ}\right)$, the entropy change $\left(\Delta \mathrm{S}^{\circ}\right)$, Gibbs free energy change $\left(\Delta \mathrm{G}^{\circ}\right)$, are calculated in a simulated human body conditions. The conformation of bovine serum albumin changed in the presence of salvianolic acid B on circular dichroism and synchronous fluorescence spectroscopy. The results show that the static quenching and non-radiative energy transfer lead to the fluorescence quenching of bovine serum albumin and salvianolic acid B-bovine serum albumin system is a spontaneous reaction, the main electrostatic force is hydrophobic effect. In addition, the addition of external common metal ions $\mathrm{Cu}^{2+}$ and $\mathrm{K}^{+}$decreased the binding constant between salvianolic acid $\mathrm{B}$ and bovine serum albumin.
\end{abstract}

Key Words: Salvianolic acid B, Bovine serum albumin, Fluorescence quenching, Interaction.

\section{INTRODUCTION}

Salvia miltiorrhiza Bge., one of the most popular traditional Chinese medicine, has been widely used for the treatment of menstrual disorder, menorrhalgia, insomnia, coronary heart diseases, angina pectoris and high cholesterol, etc. ${ }^{1,2}$. Salvianolic acid B was the main water-soluble bioactive ingredient in Salvia miltiorrhiza. Modern pharmacological studies showed that salvianolic acid B has radical scavenging, antioxidant, antitumor, antiliver fibrosis effect and can protect the heart and brain ${ }^{3-5}$.

Serum albumin, which accounted for $60 \%$ of total serum albumin in human and animal body, plays a dominant role in physiological functions. Serum albumin served as a depot and transport albumin for many endogenous and exogenous compounds in human body. The drug-albumin interaction may result in the formation of the albumin, which will affect the distribution, concentration and metabolism of the drug in the blood $^{6-8}$. Therefore, studies on the interaction between the drug and albumin will be in favour of the research of the metabolism, transporting process of the drug and clarifying the relationship between the drug and function of albumin ${ }^{9-11}$. Due to the important pharmacological actions of salvianolic acid B, it is necessary to develop an efficient and convenient method to investigate the interaction of salvianolic acid B and bovine serum albumin. Bovine serum albumin, a globulin in bovine serum which contains 582 amino acid residues, is one of the most common albumin carriers of $\operatorname{drug}^{12}$. Since bovine and human serum albumins are homologous proteins and have the similar results of all the studies on ligand-binding properties. In addition, it is low cost and ready availability. Bovine serum albumin is often selected as protein model in the interaction of drug-albumin ${ }^{13-15}$.

The aim of this study is to investigate the interaction and the effect of energy transfer between salvianolic acid B and bovine serum albumin using fluorescence spectroscopy, synchronous fluorescence spectroscopy, circular dichroism spectroscopy and ultraviolet spectroscopy. And we intend to obtain the results of the binding constants, the binding power characteristics, the binding locality and the thermodynamic parameters of the interaction, which are important to analyze pharmacological actions of salvianolic acid B.

\section{EXPERIMENTAL}

The UV-visible spectra were recorded at room temperature on a TU-1810PC UV-visible spectrophotometer (Beijing Purkinje General Co., Ltd., China) equipped with a $1 \mathrm{~cm}$ quartz cell. 
Fluorescence spectra were recorded on an F-4500 fluorescence spectrophotometer (Hitachi Limited, Japan) with $1.0 \mathrm{~cm}$ quartz cell and a temperature control device. The emission and excitation slits were $5 \mathrm{~nm}$. The synchronous fluorescence spectra were obtained by setting the excitation and emission wavelength interval $(\Delta \lambda)$ at 15 and $60 \mathrm{~nm}$. Circular dichroism measurements were made on a chirascan CD spectrometer (Applied Photophysics) using a $1.00 \mathrm{~cm}$ cell at $0.2 \mathrm{~nm}$ intervals. All of the $\mathrm{pH}$ measurements were tested using a pHS-2 digital pH-meter (Shang-hai Leici Device Works, China) in combination with a glass calomel electrode.

Bovine serum albumin ( $\geq 99 \%$ ) was purchased commercially from Huamei Bioengineering Company (Shanghai, China). A solution of bovine serum albumin $\left(2.0 \times 10^{-6} \mathrm{~mol} \mathrm{~L}^{-1}\right)$ was prepared in $\mathrm{pH} 7.4$ Tris- $\mathrm{HCl}$ buffer $\left(0.1 \mathrm{~mol} \mathrm{~L}^{-1} \mathrm{NaCl}\right.$ was used to keep ionic strength). Salvianolic acid B with purity of 99.2\% was provided by Shandong Analysis and Test Center (Shandong, China). A solution of salvianolic acid B $\left(1.0 \times 10^{-3}\right.$ mol L $\left.{ }^{-1}\right)$ was prepared in purified water. $\mathrm{Cu}^{2+}$ and $\mathrm{K}^{+}$solution $\left(2.0 \times 10^{-4} \mathrm{~mol} \mathrm{~L}^{-1}\right)$ were prepared in $\mathrm{pH} 7.4$ Tris- $\mathrm{HCl}$ buffer solution $\left(0.1 \mathrm{~mol} \mathrm{~L}^{-1} \mathrm{NaCl}\right.$ was used to keep ionic strength). All other reagents were of analytical grades and doubledistilled water was used in the experiment.

Fluorescence spectra analysis: A $3 \mathrm{~mL}$ solution containing $2.0 \times 10^{-6} \mathrm{~mol} \mathrm{~L}^{-1}$ bovine serum albumin was transferred by successive additions of $1.0 \times 10^{-3} \mathrm{~mol} \mathrm{~L}^{-1}$ salvianolic acid $\mathrm{B}$ solution and the concentration of salvianolic $B$ varied from $0-9 \times 10^{-6} \mathrm{~mol} \mathrm{~L}^{-1}$. Titrations were done manually by a microinjector. Then, the solution was scanned at the fluorophotometer at the range of $290-450 \mathrm{~nm}$, the excitation wavelength was set at $280 \mathrm{~nm}$. The fluorescence spectra were performed at three temperatures $(288,298$ and $310 \mathrm{~K})$.

Synchronization fluorescence spectra analysis: At 310 $\mathrm{K}$, the synchronous fluorescence spectrometry of bovine serum albumin titrated with various concentrations of salvianolic acid $\mathrm{B}$ were recorded at $\Delta \lambda=60 \mathrm{~nm}$ and at $\Delta \lambda=15 \mathrm{~nm}$, respectively.

Circular dichroism spectra analysis: A $400 \mathrm{~mL}$ solution containing $2.0 \times 10^{-6} \mathrm{~mol} \mathrm{~L}^{-1}$ bovine serum albumin was transferred by successive additions of $1.0 \times 10^{-3} \mathrm{~mol} \mathrm{~L}^{-1}$ salvianolic acid $\mathrm{B}$ solution and the concentration of salvianolic $\mathrm{B}$ varied from 0 to $2 \times 10^{-5} \mathrm{~mol} \mathrm{~L}^{-1}$ with three scans averaged for each circular dichroism spectrum in the range $200-250 \mathrm{~nm}$ and the results are expressed as ellipticity ([0]) in millidegrees.

UV-visible absorption spectra analysis: A $3 \mathrm{~mL}$ of solution containing $2.0 \times 10^{-6} \mathrm{~mol} \mathrm{~L}^{-1}$ bovine serum albumin was added to a colorimetric tube, then, $18 \mu \mathrm{L}$ of the solution containing $1.0 \times 10^{-3} \mathrm{~mol} \mathrm{~L}^{-1}$ salvianolic acid B was added. UV spectra of bovine serum albumin, salvianolic acid B and the mixture were recorded at room temperature. The scanning range was set at 200-400 $\mathrm{nm}$.

External conditions on the reaction (metal ions $\mathrm{Cu}^{2+}$, $\mathbf{K}^{+}$): The fluorescence spectrometry of salvianolic acid Bbovine serum albumin system were recorded in the presence of some common metal ions, viz., $\mathrm{Cu}^{2+}$ and $\mathrm{K}^{+}$in the range of $290-450 \mathrm{~nm}$ at excitation wavelength of $280 \mathrm{~nm}$ at $310 \mathrm{~K}$. The concentrations of bovine serum albumin were fixed at $2.0 \times 10^{-6} \mathrm{~mol} \mathrm{~L}^{-1}$, that of common metal ions were maintained at $2.0 \times 10^{-5} \mathrm{~mol} \mathrm{~L}^{-1}$ and that of salvianolic acid $\mathrm{B}$ was fixed at $0-9 \times 10^{-6} \mathrm{~mol} \mathrm{~L}^{-1}$.

\section{RESULTS AND DISCUSSION}

Fluorescence quenching mechanism: As the bovine serum albumin molecules containing tryptophan, tyrosine and other amino acid residues, it launched endogenous fluorescence at the wavelength range of $300-500 \mathrm{~nm}$ while salvianolic acid B does not appear fluorescence at this wavelength range. Therefore, with the increasing of salvianolic acid B, the endogenous fluorescence intensity of bovine serum albumin decreased gradually, while the shape and position of the intrinsic fluorescence peak remained unchanged. As shown in Fig. 1, the endogenous fluorescence intensity of bovine serum albumin was decreased to $50 \%$ when the concentration of the salvianolic B was $9 \times 10^{-6} \mathrm{~mol} \mathrm{~L}^{-1}$. So we can apply the fluorescence quenching of salvianolic acid B on bovine serum albumin to determine the interaction between salvianolic B and bovine serum albumin.

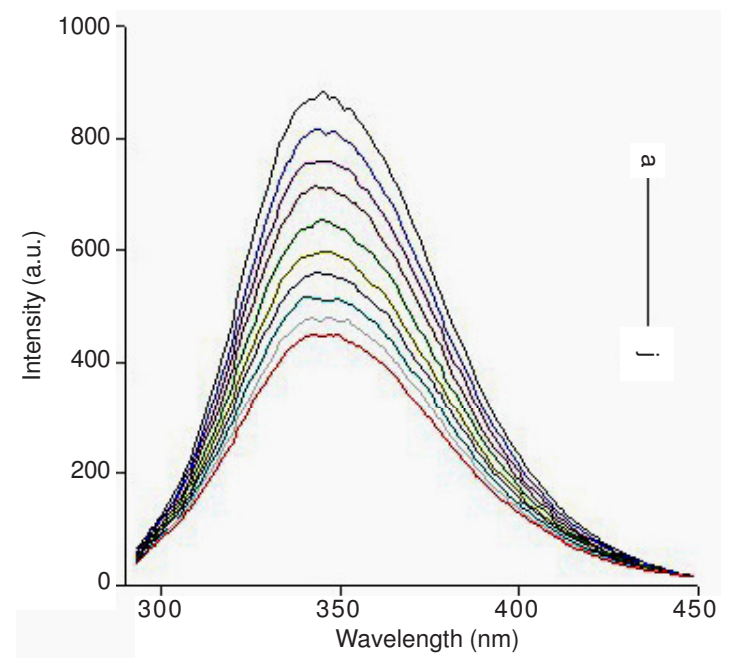

Fig. 1. Fluorescence spectra of salvianolic acid B-bovine serum albumin; $[\mathrm{BSA}]=2.0 \times 10^{-6} \mathrm{~mol} \mathrm{~L}^{-1} ;$ [salvianolic acid B a $\left.\rightarrow \mathrm{j}\right]=0,1,2,3,4$, $5,6,7,8,9\left(\times 10^{-6} \mathrm{~mol} \mathrm{~L}^{-1}\right) ; \mathrm{pH}=7.4 ; \mathrm{T}=298 \mathrm{~K}$

Generally, fluorescence quenching is divided into dynamic quenching and static quenching. For dynamic quenching following the dynamic quenching Stern Volmer equation ${ }^{16}$ :

$$
\frac{\mathrm{F}_{0}}{\mathrm{~F}}=1+\mathrm{K}_{\mathrm{q}} \tau_{0}[\mathrm{Q}]=1+\mathrm{K}_{\mathrm{sv}}[\mathrm{Q}]
$$

In this formula, $\mathrm{F}_{0}$ and $\mathrm{F}$ were the fluorescence intensities of bovine serum albumin in the absence and presence of the quencher; $\mathrm{K}_{\mathrm{q}}$ is quenching constant; [Q] is quencher concentrations of salvianolic acid $\mathrm{B}$ (because the drug concentration added in cuvette is much greater than the concentration of bovine serum albumin, so it is added directly to the drug concentration in the bovine serum albumin solution as the free drug concentration of approximately); $\mathrm{K}_{\mathrm{sv}}$ is the dynamic quenching constant, can use the formula (2) to characterize:

$$
\mathrm{K}_{\mathrm{sv}}=\mathrm{K}_{\mathrm{q}} \tau_{0}
$$

In this formula, $\tau_{0}$ is the average lifetime of the molecule without the quencher. The average lifetime of biological macromolecules is $10^{-8} \mathrm{~s}^{17}$. The maximum dynamic quenching 
constant of fluorescence quenching which agent of biological macromolecules is ca. $2.0 \times 10^{10} \mathrm{~L} \mathrm{~mol}^{-1} \mathrm{~s}^{-116}$.

According to eqn. 1, the results of fluorescence intensity (F) between salvianolic acid $B$ and bovine serum albumin were shown in Fig. 2. The slope of the curve is the quenching constant $\mathrm{K}_{\mathrm{sv}}$.

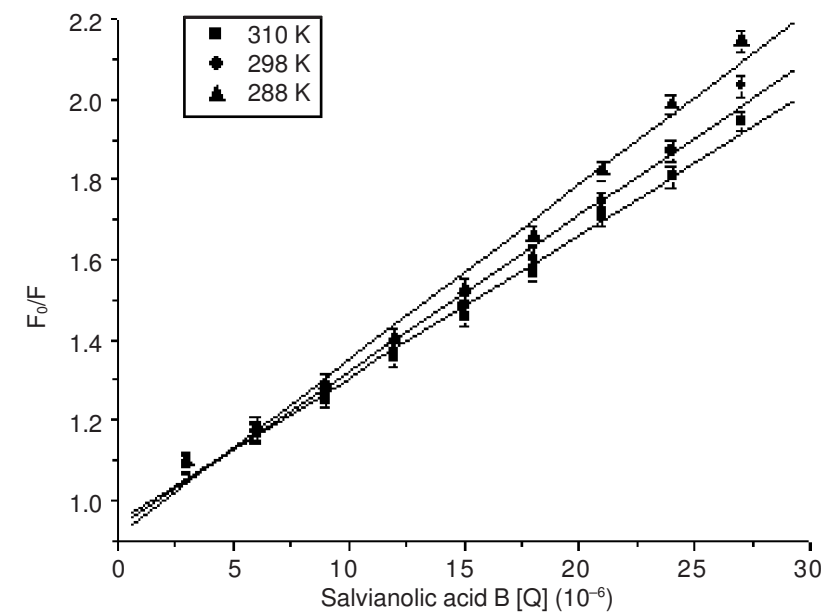

Fig. 2. Stern-Volmer plots of fluorescence quenching of bovine serum albumin by salvianolic acid B at three different temperatures

Combined with eqn. 2 , we can see that the corresponding quenching rate constants are much larger than $2.0 \times 10^{10} \mathrm{~L}$ $\mathrm{mol}^{-1} \mathrm{~s}^{-1}$ at 310,298 and $288 \mathrm{~K}$. It showed that the fluorescence quenching of salvianolic acid $\mathrm{B}$ on bovine serum albumin is not the result of dynamic collision, but of the static quenching, which was caused by the formation of drugalbumin ground-state complexes. The quenching constants at different temperatures can also be used to distinguish static quenching from dynamic quenching. If it is static quenching, with the temperature rising, the stability of complexes and the quenching constant will be reduced. As shown in Fig. 2, with the temperature increasing, the slope of the curve $\mathrm{K}_{\mathrm{sv}}$ inclined to be decreasing. As Table- 1 shown, the $\mathrm{K}$ value is decreased from $2.91 \times 10^{5}-1.09 \times 10^{5}$. Thus it is further confirmed that the quenching was static.

The UV spectrum of salvianolic acid B and bovine serum albumin was shown in Fig. 3. With the increasing of drug concentration, the absorption spectrum of the system increased. This indicates that there is the formation of ground-state complexes and the dynamic fluorescence quenching only affects the excited-state body without affecting the absorption spectra of phosphor. It is concluded that the quenching mechanism is static quenching.

Binding constant and binding sites: According to the static quenching mechanism, the static quenching data can be processed with Scatchard equation ${ }^{18}$ :

$$
\log \frac{F_{0}-F}{F}=\log K+n \log [Q]
$$

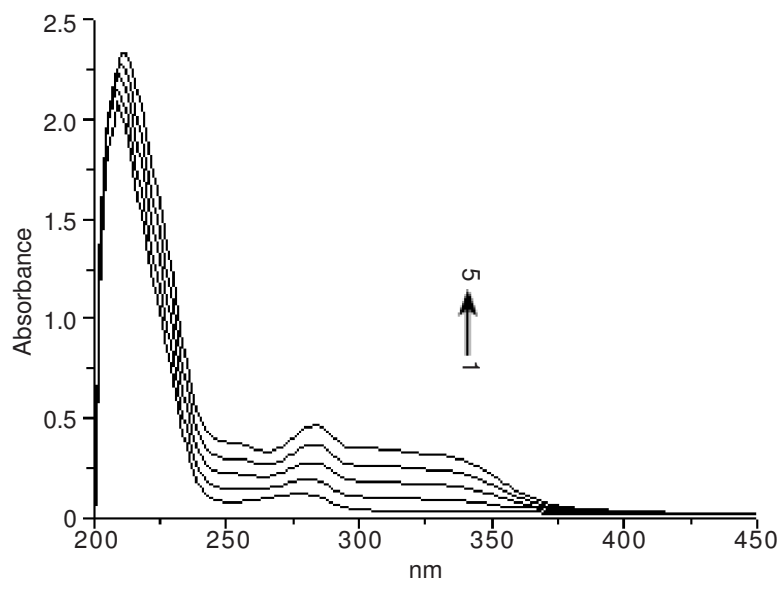

Fig. 3. UV-visible absorption spectra of bovine serum albumin in presence of the different concentrations of salvianolic acid $\mathrm{B} ;[\mathrm{BSA}]=2.0 \times$ $10^{-6} \mathrm{~mol} \mathrm{~L}^{-1}$; [salvianolic acid B $1 \rightarrow 5$ ] $=0,6,12,18,24\left(\times 10^{-6} \mathrm{~mol}\right.$ $\left.\mathrm{L}^{-1}\right) ; \mathrm{pH}=7.4 ; \mathrm{T}=298 \mathrm{~K}$

In this formula, $\mathrm{F}_{0}$ and $\mathrm{F}$ represent fluorescence intensities of bovine serum albumin in the absence and presence of the quencher; $\mathrm{K}$ is binding constant; [Q] is quencher concentrations of salvianolic acid B, $\mathrm{n}$ is binding sites. According to eqn. 3, with increasing concentration of salvianolic acid $B$, the values of $\mathrm{K}$ and $\mathrm{n}$ can be obtained (Table-1). The interaction of salvianolic acid B-bovine serum albumin system was shown in Fig. 4, the Scatchard plot, which has a good linear relationship. The data showed that salvianolic acid B-bovine serum albumin system only has one binding site and the binding constant is much bigger, which showed that salvianolic acid $\mathrm{B}$ and bovine serum albumin has a strong combination. Moreover, serum albumin in the body played a storage and transport role, therefore, the drug through the bloodstream to the site of action to take therapeutic effect.

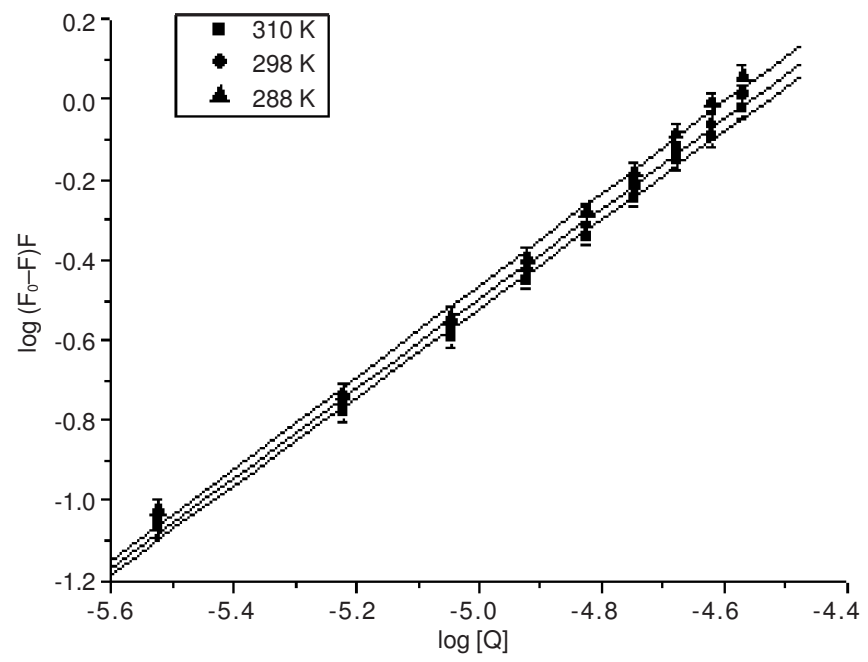

Fig. 4. Logarithmic plots of fluorescence quenching of bovine serum albumin by salvianolic acid B at three different temperatures

TABLE-1

INTERACTION PARAMETERS OF SALVIANOLIC ACID B AND BOVINE SERUM ALBUMIN AT DIFFERENT TEMPERATURES

\begin{tabular}{cccccccccc}
\hline $\mathrm{T}(\mathrm{K})$ & $\mathrm{K}_{\mathrm{sv}}\left(10^{5}\right)$ & $\mathrm{K}\left(10^{5}\right)$ & $\log \mathrm{K}$ & $\mathrm{n}$ & $\mathrm{r}(\mathrm{nm})$ & $\Delta \mathrm{H}^{\circ}(\mathrm{KJ} / \mathrm{mol})$ & $\Delta \mathrm{S}^{\circ}\left(\mathrm{J} \mathrm{mol}{ }^{-1} \mathrm{~K}^{-1}\right)$ & $\Delta \mathrm{G}^{\circ}\left(\mathrm{KJ} / \mathrm{mol}^{-1}\right)$ \\
\hline 288 & 3.92 & 2.91 & 5.4633 & 1.139 & 5.89 & -32.988 & -9.934 & -30.127 \\
298 & 3.54 & 1.83 & 5.2627 & 1.120 & 5.89 & -32.988 & -9.934 & -30.027 \\
310 & 3.30 & 1.09 & 5.0389 & 1.145 & 5.89 & -32.988 & -9.934 & -29.908 \\
\hline
\end{tabular}


Energy transfer between bovine serum albumin and salvianolic acid B: The distance between salvianolic acid B and bovine serum albumin can be calculated by Förster's dipole-dipole non-radioactive energy transfer. According to the non-radioactive energy transfer theory ${ }^{19}$, the efficiency of energy transfer is affected by the distance between the acceptor and the donor and the critical energy transfer distance ${ }^{20}$. It can be described by equation as follows:

$$
E=\frac{R_{0}^{6}}{\left(R_{0}^{6}+r^{6}\right)}=\frac{F_{0}-F}{F_{0}}
$$

where $\mathrm{E}$ is the energy transfer efficiency, calculated by $\mathrm{E}=$ $1-\mathrm{F} / \mathrm{F}_{0} . \mathrm{R}_{0}$ is the critical transfer distance of $50 \%$ transfer efficiency. $\mathrm{r}$ is the distance between the acceptor and the donor. $\mathrm{R}_{0}{ }^{6}$ can be calculated by eqn. 5 ,

$$
\mathrm{R}_{0}^{6}=8.8 \times 10^{-25} \mathrm{k}^{2} \mathrm{~N}^{-4} \mathrm{~J} \phi
$$

where $\mathrm{k}^{2}$ is the spatial of the dipole orientation factor, $\mathrm{N}$ is the refractive index of the medium in the wavelength range where the spectral overlap is significant, $F$ is the fluorescence quantum yield of the donor, $\mathrm{J}$ is the effect of the spectral overlap between the emission spectrum of the donor (bovine serum albumin) and the absorption spectrum of the receptor (salvianolic acid B) (Fig. 5), which could be calculated by the equation as follows:

$$
J=\frac{\sum F(\lambda) \varepsilon(\lambda) \lambda^{4} \Delta \lambda}{\sum F(\lambda) \Delta \lambda}
$$

where $F(\lambda)$ is the fluorescence intensity of the fluorescence donor at the wavelength $\lambda, \varepsilon(\lambda)$ is the extinction coefficient of the acceptor at wavelength $\lambda$.

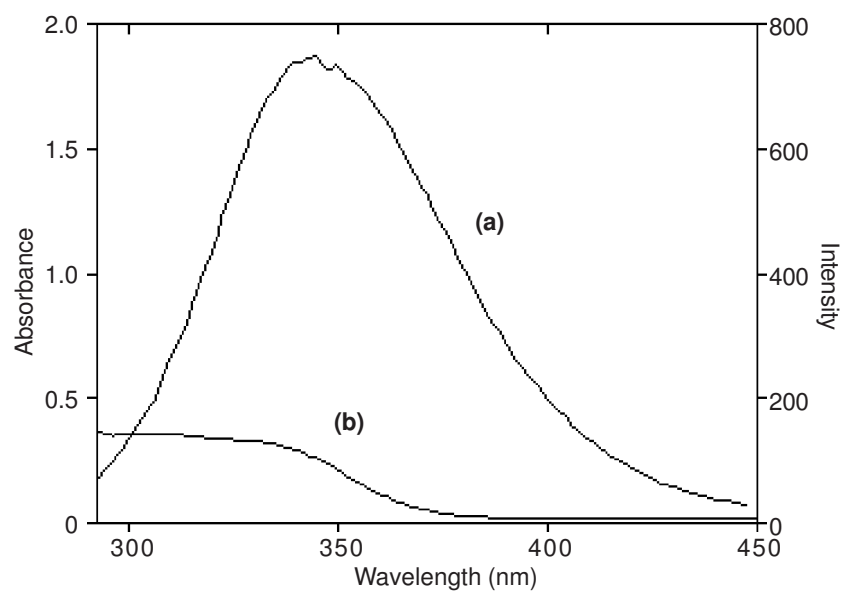

Fig. 5. Overlap of fluorescence spectrum of bovine serum albumin (a) and absorbance spectrum of salvianolic acid B (b)

The overlap of the fluorescence emission spectra of bovine serum albumin and the absorption spectra of salvianolic acid $\mathrm{B}$ at $310 \mathrm{~K}$ is shown in Fig. 5. In the present case, $\mathrm{k}^{2}=2 / 3, \mathrm{~N}$ $=1.336$ and $\Phi=0.118^{21,22}$. Combine with the eqns. 4-6, we can calculate that $\mathrm{J}$ is $4.026 \times 10^{-14} \mathrm{~cm}^{3} \mathrm{~L} / \mathrm{mol}$, then we can obtained the interaction distance $\mathrm{r}^{23,24}$ between salvianolic acid $\mathrm{B}$ and bovine serum albumin, as shown in Table-1.

Thermodynamic parameters and the nature of the binding forces: Through hydrophobic interaction, electrostatic forces, hydrogen bonding and three-dimensional van der Waals force of repulsion, drugs and albumin can form supermolecular complexes ${ }^{25,26}$. According to the thermodynamic constant before and after effect, we can determine the main type of force between the drug and albumin ${ }^{27}$. van't Hoff equation can be used to calculate the enthalpy $\left(\Delta \mathrm{H}^{\circ}\right)$ and the entropy change $\left(\Delta \mathrm{S}^{\mathrm{o}}\right)$. Then the Gibbs free energy change $\left(\Delta \mathrm{G}^{\mathrm{o}}\right)$ was calculated.

$$
\begin{gathered}
\log \mathrm{K}=-\frac{\Delta \mathrm{H}^{\mathrm{o}}}{2.303 \mathrm{RT}}+\frac{\Delta \mathrm{S}^{\mathrm{o}}}{2.303 \mathrm{R}} \\
\Delta \mathrm{G}^{\mathrm{o}}=\Delta \mathrm{H}^{\mathrm{o}}-\mathrm{T} \Delta \mathrm{S}^{\mathrm{o}}
\end{gathered}
$$

According to the formula (7) and (8), the enthalpy $\left(\Delta \mathrm{H}^{\circ}\right)$, entropy $\left(\Delta S^{\circ}\right)$ and Gibbs free energy change $\left(\Delta G^{\circ}\right)$ were obtained (Table-1). The results showed that the values of $\Delta \mathrm{H}^{\circ}$, $\Delta S^{\circ}$ are negative, which can explain that the binding reaction of salvianolic acid B with bovine serum albumin is a spontaneous process, the intermolecular forces may come from the Van der Waals forces and hydrogen bonding. However, the structure of serum albumin is complex, so it is usually with small molecules is not just a force of role alone, that is the synergy of a variety of forces ${ }^{28}$.

\section{Effect of salvianolic acid B on the conformation of bovine serum albumin}

Synchronous fluorescence spectroscopy: Because albumin is an extremely important organism in the active material, so the albumin solution conformational changes were used to explain the relationship between albumin structure and function of great significance. Currently, spectroscopy is an effective method to study the impact of small molecule to albumin conformation.

Synchronous fluorescence can be individually measured the spectral characteristics of tyrosine and tryptophan ${ }^{29}$. When $\Delta \lambda$ is $60 \mathrm{~nm}$ and $15 \mathrm{~nm}$, the fluorescence properties of tryptophan and tyrosine residues in albumin were measured, respectively. The conformational changes of bovine serum albumin in salvianolic acid B-bovine serum albumin system were studied by synchronous fluorescence spectroscopy (Fig. 6). The fluorescence of salvianolic acid B-bovine serum albumin was mainly emitted from the tryptophan residues and the contribution of tyrosine residues are little. When $\Delta \lambda$ is 60 and $15 \mathrm{~nm}$, with the increasing concentration of salvianolic acid $\mathrm{B}$, the fluorescence intensity of bovine serum albumin decreased, while the shape and position of the intrinsic fluorescence peak remained unchanged. It showed that salvianolic acid B has changed polarity microenvironment around the tryptophan and tyrosine residues. Salvianolic acid B and bovine serum albumin binding reaction enhanced the environment of the hydrophilic. It explained that the conformation of bovine serum albumin has changed.

Circular dichroism spectra: Circular dichroism method is useful to ascertain the possible influence of the interaction process on the secondary structure of the proteins. The circular dichroism spectra of bovine serum albumin in the absence (line 1) and presence of salvianolic acid B (line 2) are shown in Fig. 7. Bovine serum albumin present in the ultraviolet region at 208 and $222 \mathrm{~nm}$ two negative bands, characteristic for the $\alpha$-helical structure ${ }^{30}$. It was observed that there was an obvious reduction in the presence of salvianolic acid B without 

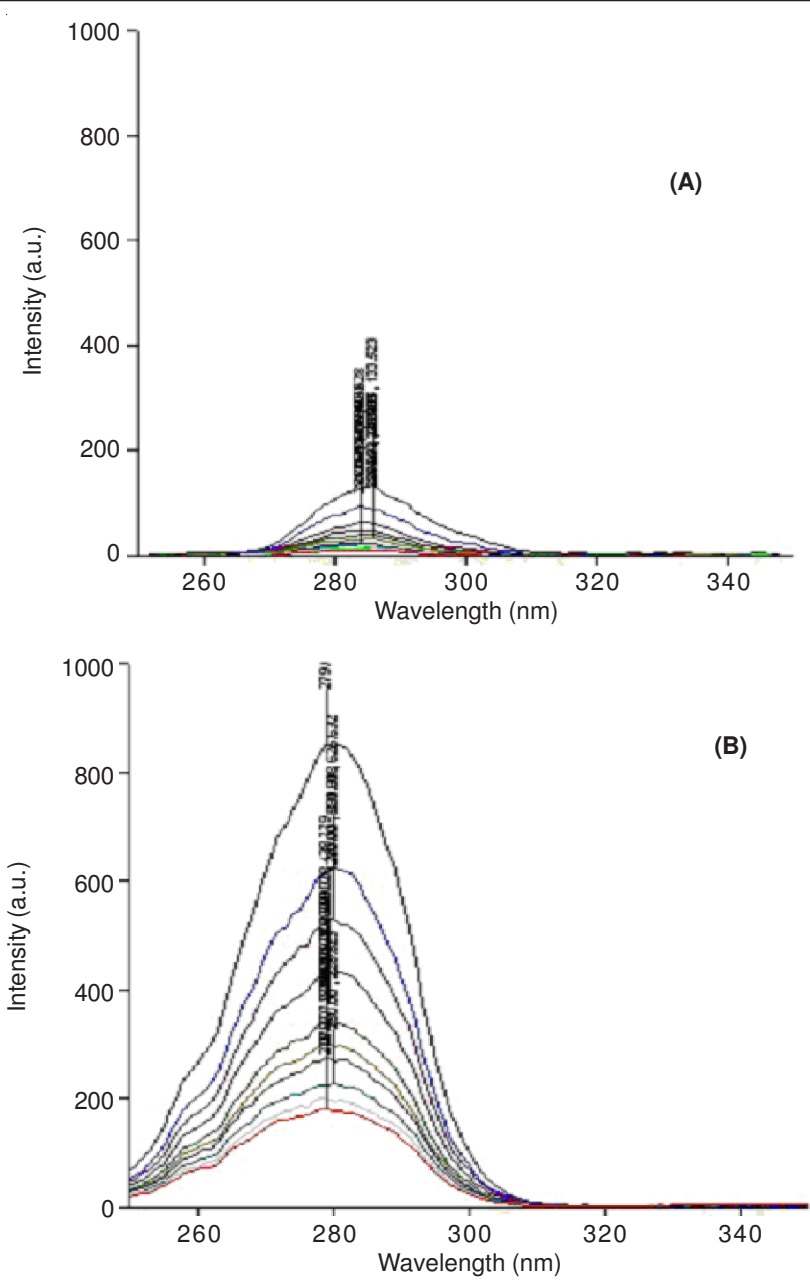

Fig. 6. Synchronous fluorescence spectra of salvianolic acid B-bovine serum albumin system A $\Delta \lambda=15 \mathrm{~nm} \mathrm{~B} \Delta \lambda=60 \mathrm{~nm}$

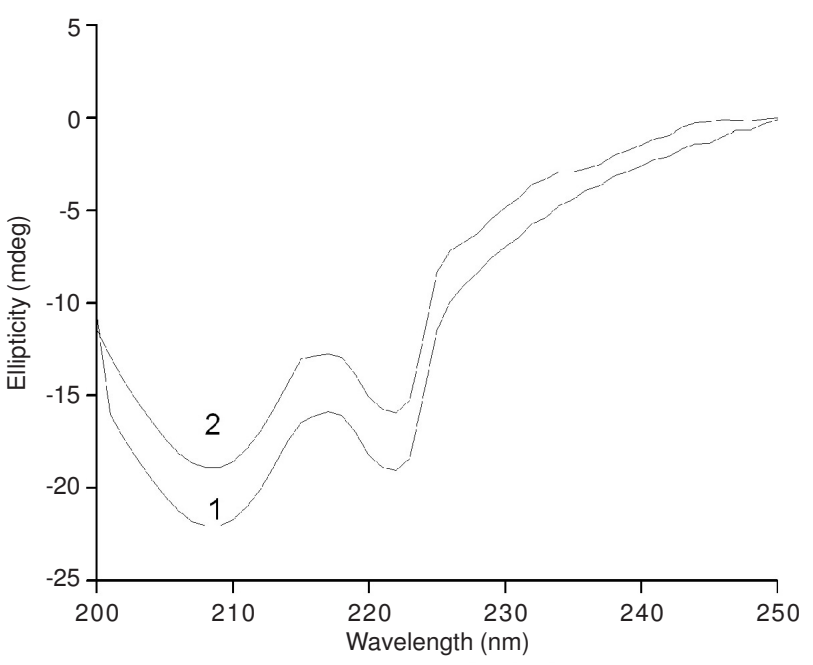

Fig. 7. CD spectra of the salvianolic acid B-bovine serum albumin system at $\mathrm{pH} 7.4[\mathrm{BSA}]=2.0 \times 10^{-6} \mathrm{~mol} \mathrm{~L}^{-1}$; molar ratios of salvianolic acid B: bovine serum albumin from 1 to 2 are 0:1 (1), 10:1 (2), respectively

any shift of two peaks. The circular dichroism results were expressed in terms of mean residue ellipticity (MRE) in deg $\mathrm{cm}^{2} \mathrm{~d} \mathrm{~mol}^{-1}$, according to the following equation:

$$
\mathrm{MRE}=\frac{\text { Observed CD }(\mathrm{m} \mathrm{deg})}{10 \mathrm{C}_{\mathrm{p}} \mathrm{nl}}
$$

where $C_{p}$ is the molar concentration of the protein, $n$ is the number of amino acid residues of the protein and 1 is the path length. The helical content of free and combined salvianolic acid $B$ was calculated from the mean residue ellipticity values at $208 \mathrm{~nm}$ using the following equation:

$$
\alpha-\text { helix }(\%)=\frac{-\mathrm{MRE}_{208}-4000}{33000-4000} \times 100
$$

Using the above equation, the $\alpha$-helicity of bovine serum albumin was calculated. It reduced from $51.38 \%$ in free bovine serum albumin to $42.03 \%$ upon binding to salvianolic acid B. The decrease of the CD signal indicated that the binding of salvianolic acid B to bovine serum albumin induced some conformational changes, but the secondary structure of bovine serum albumin remains predominantly $\alpha$-helix.

Effect of common metal ions on the binding constant of salvianolic acid B-bovine serum albumin: Some substance coexist with the serum albumin will affect the binding of small molecules and serum albumin. Metal ions have certain binding force with serum albumin ${ }^{31,32}$, they will directly affect the binding of small molecules and albumin ${ }^{33}$. To some metal ions, it will reduce the serum albumin binding constant. And with the other co-presence metal ions addition, they will improve the drugs and serum albumin binding constants. In this study, at the same temperature and $\mathrm{pH}$ value, $\mathrm{Cu}^{2+}$ and $\mathrm{K}^{+}$were added in the salvianolic acid B-bovine serum albumin system for fluorescence scanning. The results were shown in Table-2. With the addition of $\mathrm{Cu}^{2+}$ or $\mathrm{K}^{+}$, drug molecules form a competitive relationship which weakened the salvianolic acid $\mathrm{B}$ and bovine serum albumin binding. Because the two ions which were replace salvianolic acid $B$ react with the albumin. It leaded to the binding constant decreases. The decrease of binding constants will shorten the retention time of the drug in blood plasma and enhance the maximum effectiveness of the drugs, which is useful to achieve the desired therapeutic effect in a short time $\mathrm{s}^{34,35}$.

TABLE-2

METAL ION BINDING CONSTANTS OF THE REACTION

\begin{tabular}{ccccc}
\hline Metal ion & $\mathrm{T}(\mathrm{K})$ & $\mathrm{pH}$ & $\begin{array}{c}\mathrm{K} \text { (without } \\
\text { metal ion) }\left(10^{5}\right)\end{array}$ & $\begin{array}{c}\mathrm{K} \text { (within metal } \\
\text { ion) }\left(10^{4}\right)\end{array}$ \\
\hline $\mathrm{Cu}^{2+}$ & 298 & 7.40 & 1.83 & 5.79 \\
$\mathrm{~K}^{+}$ & 298 & 7.40 & 1.83 & 8.15 \\
\hline
\end{tabular}

\section{Conclusion}

The interaction between salvianolic acid B and bovine serum albumin has been investigated by fluorescence, synchronous fluorescence, circular dichroism and UV spectroscopy. The experimental results indicate that the quenching mechanism is a static fluorescence quenching procedure and the binding of salvianolic acid B to bovine serum albumin induced the conformation changes. The thermodynamic parameters indicate that the interaction is an endothermic and entropy-driven process which can occur spontaneously in vitro. The Van der Waals forces and the hydrogen bonding forces play the major roles. The paper clarified the binding interaction between salvianolic acid B and bovine serum albumin. It will provide a valuable foundation data for analysis the drug pharmacokinetic. 


\section{ACKNOWLEDGEMENTS}

Financial supports from the Key Science and Technology Program of Shandong Province (2011GGC01002) are gratefully acknowledged.

\section{REFERENCES}

1. Pharmacopoeia Commission of the People's Republic of China. Pharmacopoeia of the People's Republic of China. Beijing: Chinese MedicoPharmaceutical Sciences and Technology Publishing House (2010).

2. L. Zhou, Z. Zuo and M.S. Chow, J. Clin. Pharmacol., 45, 1345 (2005)

3. H.L. Wu, Y.H. Li, Y.H. Lin, R. Wang, Y.B. Li, L. Tie, Q.L. Song, D.A. Guo, H.M. Yu and X.J. Li, Cardiovasc. Res., 81, 148 (2009).

4. Y.H. Chen, G.H. Du and J.T. Zhang, Acta Pharmacol. Sin., 21, 463 (2000).

5. M.K. Tang, D.C. Ren, J.T. Zhang and G.H. Du, J. Phytomed., 9, 405 (2002).

6. L. Trnková, I. Boušová, V. Stanková and J. Dršata, J. Mol. Struct., 985 , 243 (2011)

7. T. Peters, All About Albumin: Biochemistry, Genetics and Medical Applications, Academic Press, San Diego (CA), Ch. 2 and 3 (1996).

8. D.C. Carter and J.X. Ho, Adv. Protein Chem., 45, 153 (1994).

9. J. Seetharamappa and B.P. Kamat, Chem. Pharm. Bull., 52, 1053 (2004).

10. B. Pal, P.K. Bajpai and T.S. Basu Baul, Spectrochim. Acta A, 56, 2453 (2000).

11. H. Xu, S.L. Gao, J.B. Lv, Q.W. Liu, Y. Zuo and X. Wang, J. Mol. Struct., 919, 334 (2009).

12. F. Wang, W. Huang, B. Tang and X.J. Liu, Chin. J. Anal. Chem., 34, s239 (2006).

13. G.W. Zhang, A.P. Wang, T. Jiang and Q.M. Que, Chin. J. Anal. Lab., 27, 1 (2008).

14. M. He, Z.N. Xia, Y.G. Yin and Z. Liu, Chin. J. Modern Appl. Pharm., 21 (2004).

15. J.Q. Tong, H.X. Zhang, H.M. Yang and P. Mei, J. Mol. Biol. Rep., 37, 1741 (2010)
16. G.Z. Chen, Fluorescence Analysis, Science Press, Beijing, p. 122 (1990).

17. D.M. Zha, S. Li, Y.F. Yang, C.Q. Tu and H. Liang, Spectrosc. Spectr. Anal., 19, 21 (1999).

18. W.Y. He, Y. Li, J.H. Tang, F. Luan, J. Jin and Z.D. Hu, J. Biol. Macromol., 39, 165 (2006).

19. T. Förster and O. Sinanoglu, Modern Quantum Chem., Academic Press, New York, Vol. 3, pp. 93-137 (1966).

20. X.Y. Yu, R.H. Liu, F.X. Yang, D.H. Ji, X.F. Li, J. Chen, H.W. Huang and P.G. Yi, J. Mol. Struct., 985, 407 (2011).

21. Z.C. Shang, P.G. Yi, Q.S. Yu and R.S. Lin, Acta Phys. Chim. Sin., 17, 48 (2001).

22. H. Lin, J.F. Lan, M. Guan, F.L. Sheng and H.X. Zhang, Spectrochim. Acta A, 73, 936 (2009)

23. Z.L. Yu, D.J. Li, B.M. Ji and J.J. Chen, J. Mol. Struct., 889, 422 (2008).

24. G.K. Wu, C.N. Yan and Y. Liu, Guang Pu Xue Yu Guang Pu Fen Xi, 28, 2139 (2008).

25. K. Yamasaki, T. Maruyama, A. Takadata, A. Suenaga, U. Kragh-Hanse and M. Otagiri, J. Pharm. Sci., 93, 3004 (2004).

26. H. Yang, Z.Q. Wang, Y.C. Wang and K.Y. Ni, Chin. J. Spectrosc. Lab., 25, 284 (2008).

27. J. Gonzalez-Jimenez, H. Jacquotte and I. Cayre, Chem. Biol. Interact., 84, 221 (1992).

28. P.D. Ross and S. Subramanian, Biochemisty, 20, 3096 (1981)

29. G.Z. Chen, X.Z. Huang, J.J. Xu and Z.Z. Zheng, Fluorescence Analysis, M. Beijing: Science Press, pp. 201-213 (1990).

30. A. Varlan and M. Hillebrand, Molecules, 15, 3095 (2010).

31. H. Liang, H. Jin, Q.T. Chu, M. Zhang, Y.Q. Zhou and P.W. Shen, J. Inorg. Biochem., 85, 167 (2001).

32. P.J. Sadler, A. Tucker and J.H. Viles, Eur. J. Med. Chem., 220, 193 (1994).

33. W. Bal, J. Christodoulou, P.J. Sadler and A. Tucker, J. Inorg. Biochem., 70, 33 (1998)

34. N. Wang, L. Ye, B.Q. Zhao and J.X. Yu, Braz. J. Med. Biol. Res., 41, 589 (2008)

35. G.W. Zhang, Q.M. Que and J.H. Pan, Guang Pu Xue Yu Guang Pu Fen Xi, 27, 1784 (2007). 